\title{
Novel Materials and Structures Fabricated by Electron Beam Melting
}

\author{
Harvey West ${ }^{1}$, Ola Harrysson ${ }^{1}$, Tim Horn ${ }^{1}$, Denis Cormier ${ }^{2}$, Ron Aman ${ }^{2}$, and Denis Marcellin-Little ${ }^{3}$ \\ ${ }^{1 .}$ Edward P. Fitts Dept. of Industrial and Systems Engineering, N.C. State University, Raleigh, NC. \\ 2. Dept. of Industrial and Systems Engineering, Rochester Institute of Technology, Rochester, NY. \\ 3. Dept. of Clinical Sciences, College of Veterinary Medicine, N.C. State University, Raleigh, NC.
}

Researchers in the Center for Additive Manufacturing and Logistics (CAMAL) in the Edward P. Fitts Department of Industrial and Systems Engineering at North Carolina State University have been active in the area of additive manufacturing since 2000, and have gained an international reputation for their research and educational efforts. While, historically, the first rapid prototyping machines were created to produce parts from thermoset or thermoplastic polymers, the additive manufacturing of metal components has become the most important research topic for a wide variety of industries including aerospace, medicine, power industry, and the military. NCSU was the first user of Electron Beam Melting (EBM) technology in the world when, in 2003, the world's first EBM machine was acquired from Arcam AB (Mölndal, Sweden). This technology allows for production of fully dense metal parts using an electron beam to selectively fuse layers of metal powder.

The Arcam EBM machine was originally designed to process powders of $\mathrm{H} 13$ tool steel for the direct production of injection molding dies. Figure 1a shows the typical as-produced martensitic microstructure of this material [1]. Electron beam melting also allows the fabrication of complex shapes from materials that do not possess sufficient ductility for forging, or are difficult to cast. One of the first materials targeted was GRCop-84. This copper alloy gains its high temperature strength and creep resistance from a fine dispersion of $\mathrm{Cr}_{2} \mathrm{Nb}$ particulates, and can only be processed by powder metallurgy techniques since casting results in coarsening of the second phase. However, as can be seen in Figure $1 \mathrm{~b}$, when processed by EBM, the microstructure retains the size and distribution of the dispersoids [2]. Another high temperature material investigated for processing by EBM was the intermetallic $\gamma$-TiAl [3]. Avio Aero is planning to use EBM technology instead of casting to fabricate turbine blades from this lightweight alloy. Other alloys that have been successfully processed at NCSU are Inconel 625 and 718, niobium, nitinol, high purity copper, and aluminum alloys 2024, 6061, and 7075. Electron beam melting can also be used to consolidate non-metallics such as the metal oxides present in lunar regolith simulant. The obvious difficulty with this material is the dissipation of the beam current through the material to ground, but by adjusting the beam conditions, fusing of the material is possible as shown in Figure 2 .

At the suggestion of Dr. Harrysson, in 2003, Arcam began developing the machine control parameters for processing Ti6Al4V powder. With this new material available, the EBM system could be used to fabricate components for the medical and aerospace industries. Figure 3a shows the as-produced microstructure of this alloy [4]. One main advantage of the additive manufacturing process is that it allows the fabrication of structures that could not be produced conventionally. Figure $3 \mathrm{~b}$ shows a custom transdermal osseointegrated implant fabricated for a canine patient in the College of Veterinary Medicine. Instead of making fully solid parts, incorporating mesh structures into implants can reduce the overall stiffness, and encourage bone ingrowth. Mesh structures can also be used to reduce the weight of aerospace components. However, the surface roughness of the mesh struts (Figure 3c), while appropriate for biological applications, may contribute to poor fatigue performance, and strategies to improve surface finish of as-processed or post-processed parts are being investigated. 
Additional research at CAMAL involves the design of alloys specifically tailored for additive processes. For instance, the addition of elements to promote grain refinement could reduce the anisotropy that accompanies the growth of grains along the build direction (Figures $4 \mathrm{a}$ and $4 \mathrm{~b}$ ) [5]. Also, characterizing the effect of powder morphology and size distribution on the properties of parts built by additive manufacturing is essential for developing new materials or material systems (Figure 5).

[1] D Cormier et al, Rapid Prototyping Journal 10 (2004) p. 35.

[2] T Mahale, Ph.D. dissertation, N.C. State University (2009).

[3] D Cormier et al, Research Letters in Materials Science 2007 (2007) p. 1.

[4] D Cormier et al, Proceedings of the 15th Solid Freeform Fabrication Symposium (2004).

[5] T Horn et al, Proceedings of Materials Science \& Technology (2014).
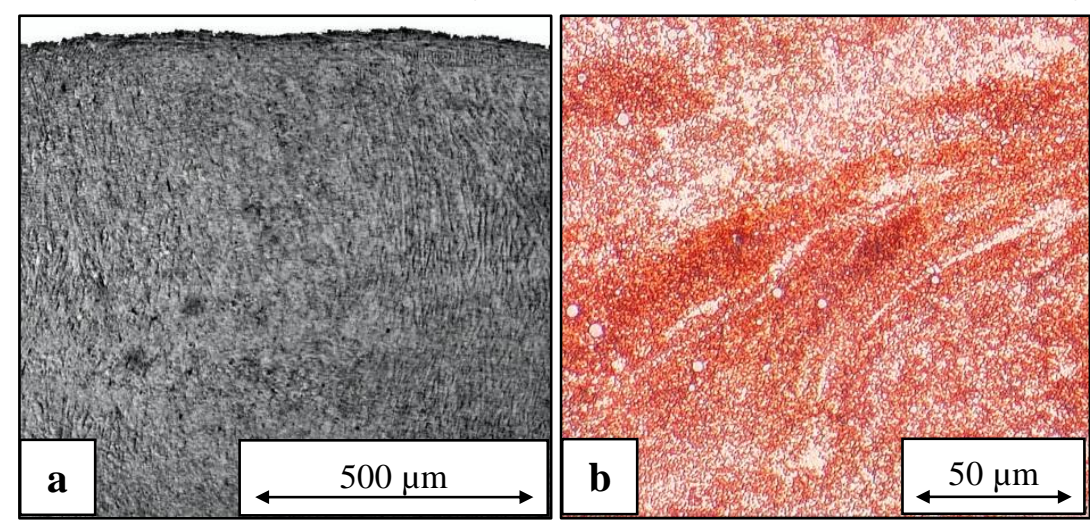

Figure 1. Microstructures of (a) H13 tool steel, (b) GRCop-84
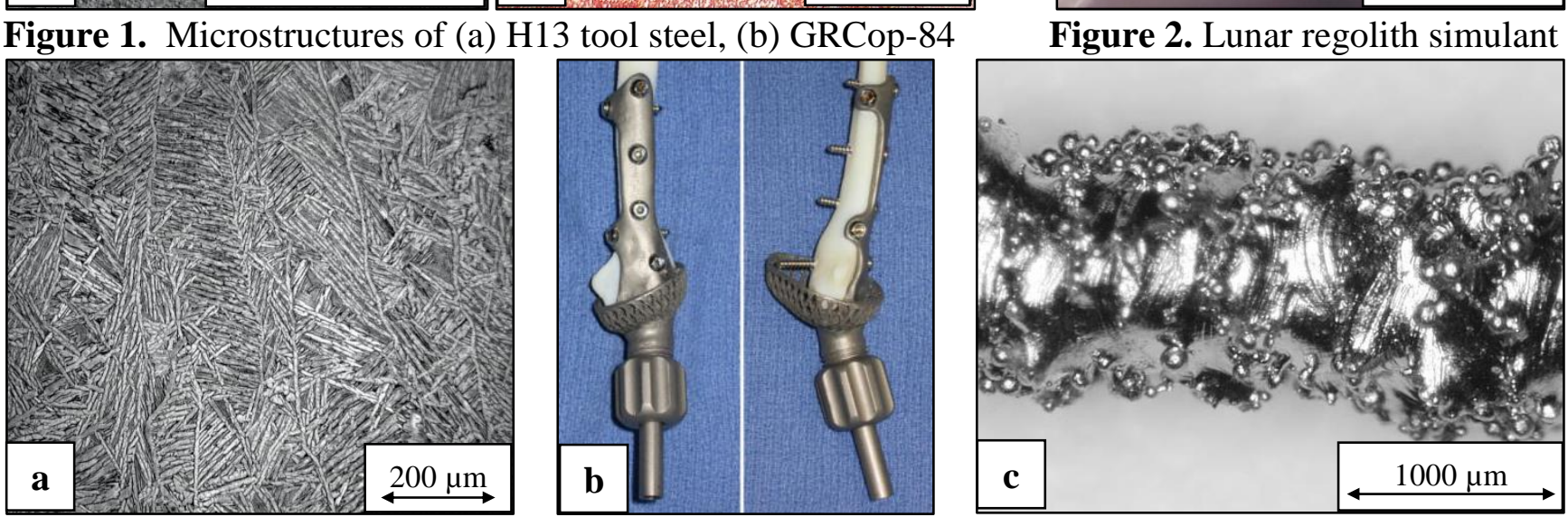

Figure 3. Ti6Al4V (a) microstructure, (b) custom implant, (c) as-fabricated mesh strut
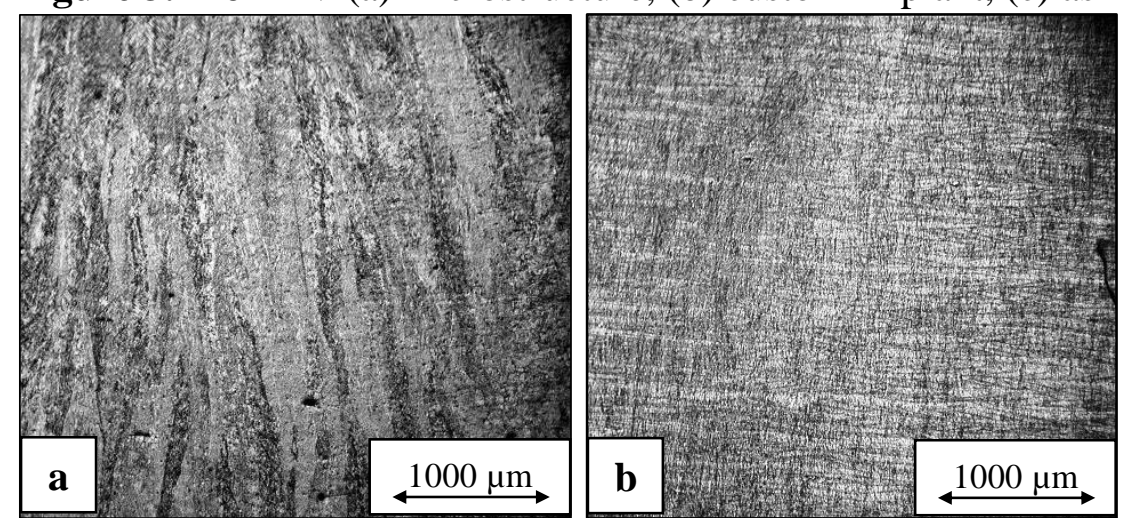

Figure 4. (a)100\% Ti6Al4V, (b) Ti6Al4V+1\%B

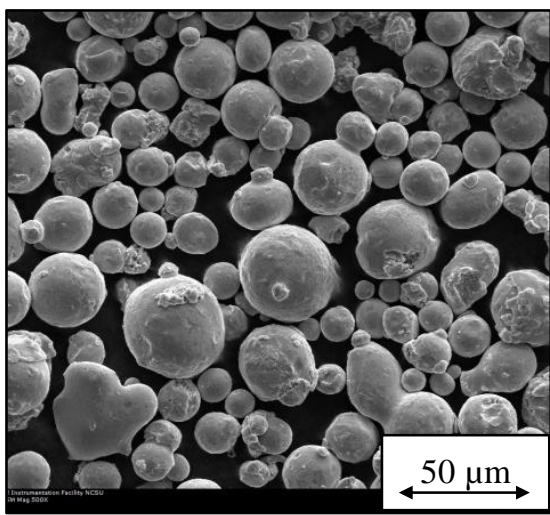

Figure 5. Powder examination 